\title{
Study of the geomechanical behaviour of different saline typologies in the Catalan basin
}

\author{
Nor Sidki ${ }^{1}$, Marc Bascompta ${ }^{2}$, Lluís Sanmiquel ${ }^{2}$ \\ ${ }^{1}$ Department of Mining Engineering, Industrial and ICT \\ Polytechnic University of Catalonia (UPC), Avenue Bases de Manresa, 61-73, 08242-Manresa Spain \\ nor.sidki@upc.edu \\ ${ }^{2}$ ICL Chair in Sustainable Mining. \\ Polytechnic University of Catalonia (UPC), Avenue Bases de Manresa, 61-73, 08242-Manresa Spain \\ marc.bascompta@upc.edu; lluis.sanmiquel@upc.edu
}

\section{Extended Abstract}

Saline materials have a characteristic called Creep, which is the flow capacity once an underground excavation is opened. This flow can be fast enough to present a safety hazard for the miners and an operational issue due to the crosssection reduction of the drift or even its collapse. Therefore, it is crucial to control the creep evolution over time.

A case study is analysed, analysing 8 salt lithologies separated by layers of clays that configure the deposit. The properties of these clays, considering its surfaces, correspond to the weakness planes, being the most likely zone to detach and cause accidents. Consequently, they have been analysed to know their properties, as well as the movements that occur in the drifts.

In this regard, a laser scan has been used to determine the movements generated over time by means of weekly data obtaining a pattern, movements of lithologies and its velocity, and the load of the pillars in the area studied. 